\title{
Clinical significance of airway mucus hypersecretion in chronic obstructive pulmonary disease
}

\author{
Pan-wen Tian, Fu-qiang Wen \\ Department of Respiratory Medicine, West China Hospital, Sichuan University, \\ Chengdu 610041, Sichuan Province, China
}

Address for Correspondence: Fu-qiang Wen,

Department of Respiratory Medicine

West China Hospital, Sichuan

University, Chengdu 610041

Sichuan Province, China

E-mail: wenfuqiang@126.com

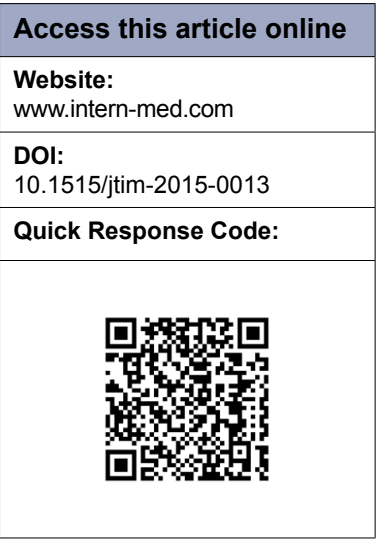

\section{ABSTRACT}

Airway mucus hypersecretion is one of the most important features of chronic obstructive pulmonary disease (COPD). Airway mucus hypersecretion in COPD patients results in outcomes such as rapid decline of lung function, poor quality of life, and high rate of acute exacerbation, hospitalization and mortality. Nonpharmacologic treatments for airway mucus hypersecretion in COPD include smoking cessation and physical rehabilitation. Pharmacologic therapies include expectorants, mucolytics, methylxanthines, beta-adrenergic receptor agonists, anticholinergics, glucocorticoids, phosphodiesterase-4 inhibitors, antioxidants, and antibiotics. Novel drugs with promising prospects are currently under clinical trials.

Key words: pulmonary disease, chronic obstructive; mucus hypersecretion

\section{INTRODUCTION}

Chronic obstructive pulmonary disease (COPD), mainly characterized by constant and progressive airflow obstruction, is chronic inflammation of the airways and lungs exposed to harmful granules or air. It is estimated by WHO that over 200 million people worldwide are suffering from COPD and it might rank third among killer diseases by $2030^{[1]}$. Airway mucus hypersecretion is one of the most important features of COPD, clinically manifested as repeated cough and expectoration. It is more than a symptom; rather, it is an independent risk factor for COPD progression and prognosis ${ }^{[2]}$. COPD complicated with airway mucus hypersecretion has become a hot topic in the field of pulmonary diseases, because the treatment of airway mucus hypersecretion is of vital clinical significance for COPD patients.

\section{PATHOGENESIS OF AIRWAY MUCUS HYPERSECRETION}

The pathogenesis of airway mucus hypersecretion in COPD is complicated, involving inflammation, oxidative stress, proteinase balance, and signal transduction pathways. In chronic inflammatory disorder of the airways, long-term and repeated inflammatory stimuli cause extensive metaplasia of bronchial epithelial goblet cells, and hypertrophy and hyperplasia of submucosal bronchial glands, which result in blockage of the respiratory tract, obstruction of airflow, and accelerated decline of lung function, leading to deterioration and increase of acute exacerbation rate ${ }^{[3]}$; in the meantime, inflammatory reactions make cilia unable to function normally, lose surfactants, and biochemical properties of mucus change so that mucus retains within the airways and forms plugs, which worsens blockage of narrowed airway and pathogen colonization, leading to constant infection, obstruction, and reconstruction of respiratory tract.

\section{EFFECTS OF AIRWAY MUCUS HYPERSECRETION ON COPD PATIENTS}

\section{Lung function}

Chronic airway mucus hypersecretion can cause progressive decline in pulmonary 
function among COPD patients. A 12-year follow-up study of 1,757 males and 2,191 females reveals the relation between chronic phlegm and $\mathrm{FEV}_{1}$ decline after adjustment for age and cigarette smoking ${ }^{[4]}$. In the study, men and women with chronic phlegm show $\mathrm{FEV}_{1}$ decline of $(4.5 \pm 2.0) \mathrm{ml} / \mathrm{yr}$ and $(1.7 \pm 1.5) \mathrm{ml} / \mathrm{yr}$, respectively ${ }^{[4]}$. Vestbo and others made a 5-year follow-up study on 5,354 women and 4,081 men and found that chronic airway mucus hypersecretion was significantly associated with $\mathrm{FEV}_{1}$ decline among COPD patients ${ }^{[5]}$. The study shows that chronic airway mucus hypersecretion is associated with an excess $\mathrm{FEV}_{1}$ decline of $22.8 \mathrm{ml} / \mathrm{yr}$, compared with men without airway mucus hypersecretion after adjusting for age, height, weight, and smoking; in women, the excess decline was $12.6 \mathrm{ml} / \mathrm{yr}$.

\section{Quality of life}

Several large-scale clinical research studies indicate that chronic phlegm is closely associated with limitation of activity and worsening quality of life. Kim and others have found that chronic bronchitis (CB) in patients with COPD is associated with modified medical British research council (mMRC) and St George Respiratory Questionnaire (SGRQ) scoring ${ }^{[6]}$. ECLIPSE investigators have found that $\mathrm{CB}$ in patients with various degrees of COPD (GOLD II $\sim$ IV grades) is associated with mMRC and SGRQ score decline $^{[7]}$. The PLATINO study has found that COPD patients with $\mathrm{CB}$ had worse general health status and physical activity limitation ${ }^{[8]}$.

\section{Acute exacerbation and hospitalization}

Vestbo and others have found that chronic airway mucus hypersecretion in patients with COPD is associated with a significant increase in risk for acute exacerbation and hospitalization: In men, the risk increased 2.4 times and in women, 2.6 times $^{[5]}$. A multi-center clinical observational study on 433 COPD patients shows that in those with chronic cough and phlegm, the risk for acute exacerbation increased 4.15 times and that for the following hospitalization increased 4.08 times $^{[0]}$. However, not all the relevant studies have similar findings. ECLIPSE and PLATINO studies have not detected any association between chronic cough and phlegm among COPD patients and rate of acute exacerbation ${ }^{[7-8]}$.

The differences in research results should be analyzed objectively, because they are caused by multiple factors including setting, subjects (such as race, severity, and smoking), and design. Therefore, more large-scale prospective studies are needed to determine whether chronic cough and phlegm are related to acute exacerbation and hospitalization.

\section{Mortality}

Chronic cough and phlegm significantly increase death risk. In a clinical study, 1,711 middle-aged men were followed up for up to 40 years; the statistical analysis shows that persistent cough and phlegm increased death risk related to respiratory disorders by 2.54 times and total death risk by 1.64 times after adjusting for lung function ${ }^{[10]}$. Prescott and others followed up 14,223 COPD patients for 10 to 12 years and found that chronic airway mucus hypersecretion increased death risk related to lung infections by 3.5 times $^{[11]}$. Speizer and others followed up 8,427 COPD patients for 12 years and found that chronic cough and phlegm significantly increased death risk: In men, the risk increased by 3.75 times and in women, 11.04 times $^{[12]}$.

\section{TREATMENTS FOR AIRWAY MUCUS HYPERSECRETION}

The treatments should counteract each factor contributing to the pathogenesis of airway mucus hypersecretion, for example, to decrease excessive mucus production, inhibit inflammation, clear mucus by increasing cilia transport, reduce mucus viscidity, enhance airway shear stress, to relieve cough and phlegm. Generally, the treatments are divided into two categories: pharmacologic and nonpharmacologic.

\section{Nonpharmacologic treatments \\ Smoking cessation}

Smoking cessation can relieve cough in patients with chronic cough and phlegm. It can improve mucus cilia functions, inhibit goblet cell hyperplasia, and repair airway injuries. The sputum of those who quit smoking contains less mucus than that of persistent smokers. A large-scale clinical research by Pelkonen and others shows that the incidence of chronic cough and phlegm among smokers $(42 \%)$ is significantly higher than that of nonsmokers $(26 \%)^{[10]}$.

\section{Physical rehabilitation}

Cough and increased minute ventilation may help to clear airway mucus. With the increase in minute ventilation, airflow production and mucus shear stress increase. Physical therapy can moisten airways and regulate mucus hydration. Thus, forced expirations (directed cough or huff), or shaking might benefit patients with chronic cough and phlegm ${ }^{[13]}$. However, physical therapy has not been proved in large-scale clinical research.

\section{Pharmacologic treatments}

Expectorants and mucolytics

Guaifenesin can stimulate the vagus nerve and increase respiratory secretion to promote the discharge of sputum. 
Yet, COPD patients cannot benefit from long-term use of guaifenesin. A clinical research on COPD patients shows that hypertonic saline could absorb the water within airway epithelial cells, hydrate mucus and induce cough, and also improve breathing and exercise tolerance ${ }^{[14]}$.

Methylxanthines and beta-adrenergic receptor agonists

Methylxanthines and beta-adrenergic receptor agonists can remove mucus. Such medications can augment airway lumen diameter, promote cilia motion by increasing cyclic adenosine monophosphate in cells, and activate transmembrane regulators to induce chloride ion secretion and mucus hydration, resulting in airway cilia transport. Long-acting beta-adrenergic receptor agonists can promote mucociliary function and increase peak expiratory flow rate, thus relieving cough. In vitro studies suggest that salmeterol could promote cilia motion and increase ciliary beat frequency. Similarly, formoterol could improve mucociliary function of COPD patients ${ }^{[15]}$.

\section{Anticholinergics}

Anticholinergics, muscarinic receptor antagonists, can increase airway lumen diameter and decrease mucus secretion, thus removing mucus. Yet, they can reduce airway surfactant fluid and make airway secretions dry and difficult to remove. Clinical studies suggest that ipratropium bromide could reduce cough frequency and severity and enhance lung functions, but could not improve mucociliary function ${ }^{[16]}$.

\section{Glucocorticoids}

In vitro studies show that glucocorticoids can alleviate inflammation and reduce mucus production. In vivo studies suggest that dexamethasone can downregulate the expression of MUC5AC, a mucin gene in human airway epithelial cells, and enhance mucociliary function. Inhaled glucocorticoids could lower the rate of acute exacerbation and improve quality of life among COPD patients. However, whether they can relieve chronic cough and phlegm is still unknown ${ }^{[17]}$.

Phosphodiesterase-4 (PDE4) inhibitors

PDE4, a major cAMP-metabolizing enzyme in inflammation, plays an important mediating role in the synthesis and release of airway nonadrenergic, noncholinergic neurotransmitters. PDE4 inhibitors can relieve inflammation and relax airway smooth muscle. A systemic review of 23 randomized clinical trials on roflumilast or cilomilast versus placebo shows that PDE4 inhibitors could increase $\mathrm{FEV}_{1}$ by $45.59 \mathrm{ml}(95 \% \mathrm{CI}$ $39.1 \sim 52.03)$ and reduce rate of acute exacerbation (OR $0.78,95 \%$ CI $0.72 \sim 0.85)^{[18]}$. Two clinical studies evaluated the effects of roflumilast on patients with moderate to severe COPD, most of whom $(78 \% \sim 100 \%)$ had chronic cough and phlegm before entering the studies. In one study, the subjects were randomly divided into roflumilast combined with salmeterol and salmeterol groups ${ }^{[19]}$, while in another, the subjects were randomly divided into roflumilast combined with tiotropium bromide and tiotropium bromide groups ${ }^{[20]}$. Both studies prove that roflumilast can significantly increase $\mathrm{FEV}_{1}$ and reduce rate of acute exacerbation. The studies indicate that PDE4 inhibitors can benefit COPD patients with chronic cough and phlegm.

\section{Antioxidants}

Drugs targeting oxidative stress, an important part of COPD pathogenesis, can benefit the patients. Sulfhydryl compounds including $\mathrm{N}$-acetyl-L-cysteine (NAC), carbocisteine, erdosteine, and fudosteine are effective antioxidants, among which NAC and carbocisteine are studied in detail. NAC, the $\mathrm{N}$-acetyl derivative of L-cysteine, can decrease reduced glutathione, cellular oxidative stress, and reactive oxygen species (ROS) production. It can also reduce disulfide and thiol bonds associated with mucin polymer and lower mucus viscosity. In vitro studies show that carbocisteine, the mercaptan derivative of L-cysteine, can remove free radicals, inhibit inflammation, and reduce mucus viscosity by acting on fucose and sialic acid. In a multi-center study, 523 patients with COPD, whose average baseline $\mathrm{FEV}_{1}$ accounted for $57 \%$ of expected value, were randomly assigned to NAC or placebo and followed for 3 years. It was found that the average number of exacerbations per year among all the subjects was 2.4 2.5. The number did not differ between groups; neither did the yearly rate of decline in $\mathrm{FEV}_{1}$. Yet, subgroup analysis suggested that the exacerbation rate of patients treated with NAC reduced significantly compared with that of those not treated with inhaled corticosteroids (accounting for $30 \%$ of all the subjects) or those treated with placebo ${ }^{[21]}$. In a double-blind randomized placebocontrolled study in 34 centers in China, 1,006 patients with moderate to severe COPD aged from 40 to 80 were randomly assigned to $600 \mathrm{mg}$ NAC twice a day or placebo. After one year follow-up, it was found that the number of acute exacerbation per year of NAC group was 1.16 and that of placebo group was 1.49 , suggesting that the exacerbation rate of NAC group was reduced significantly (RR 0.78, 95\%CI 0.67 0.90, $P<0.05$ ). However, the study does not evaluate the effects of NAC on chronic cough and phlegm among COPD patients ${ }^{[22]}$.

\section{Antibiotics}

Macrolide antibiotics may alleviate chronic cough and phlegm among COPD patients. Macrolide antibiotics can inhibit pro-inflammatory factors, decrease neutrophil influx, impair neutrophil migration, induce apoptosis, relieve 
eosinophilic inflammation, increase cilia transport, reduce goblet cell secretion, and alleviate bronchial contraction. In a clinical study, 109 COPD patients were randomly assigned to $250 \mathrm{mg}$ erythromycin twice a day or placebo. After one year, the exacerbation rate of erythromycin group was significantly lower than that of placebo group ${ }^{[23]}$. In a large-scale prospective placebo-controlled study published in NEJM in 2011, COPD patients were randomly divided into $250 \mathrm{mg}$ azithromycin and placebo groups. After one year follow-up, it was found that the exacerbation rate was significantly decreased and quality of life was improved in the azithromycin group ${ }^{[24]}$.

\section{Novel drugs}

Our research team has found that myristoylated alaninerich C kinase substrate (MARCKS) is an important factor in airway mucus secretion and inflammation regulation; MARCKS-related peptide promotes the release of inflammatory mediators within airway epithelial cells in a rat model of airway mucus hypersecretion induced by acrolein, a toxic component of cigarettes ${ }^{[25]}$. BIO-11006, a new inhalation drug targeting patients with chronic cough and phlegm, is under Phase II study (BREATH 1trial) ${ }^{[26]}$. BIO-11006 can inhibit MARCKS. Preliminary studies have shown that the new medication can improve lung function and relieve symptoms such as cough and phlegm in COPD patients, which suggests that it may benefit COPD patients with chronic cough and phlegm.

\section{Conflicts of Interest}

None declared.

\section{REFERENCES}

1. World Health Organization. World Health Statistics 2008 [EB/OL]. Available at: http://www.who.int/whosis/whostat/EN_WHS08_Full. pdf. Access on March 23, 2015.

2. Fahy JV, Dickey BF. Airway mucus function and dysfunction. N Engl J Med 2010; 363: 2233-47.

3. Guo W, Zhang J. Study and clinical treatment of patients with chronic obstructive pulmonary disease of airway mucus hypersecretion. Chin J Pract Intern Med 2007; 27: 1390-4.

4. Sherman CB, Xu X, Speizer FE, Ferris BG Jr, Weiss ST, Dockery DW. Longitudinal lung function decline in subjects with respiratory symptoms. Am Rev Respir Dis 1992; 146: 855-9.

5. Vestbo J, Prescott E, Lange P. Association of chronic mucus hypersecretion with FEV1 decline and chronic obstructive pulmonary disease morbidity. Am J Respir Crit Care Med 1996; 153: 1530-5.

6. Kim V, Han MK, Vance GB, Make BJ, Newell JD, Hokanson JE, et al. COPD Gene Investigators. The chronic bronchitic phenotype of COPD: an analysis of the COPD Gene Study. Chest 2011; 140: 626-33.

7. Agusti A, Calverley PM, Celli B, Coxson HO, Edwards LD, Lomas DA, et al. Characterisation of COPD heterogeneity in the ECLIPSE cohort. Respir Res 2010; 11: 122.
8. de Oca MM, Halbert RJ, Lopez MV, Perez-Padilla R, Tálamo C, Moreno $\mathrm{D}$, et al. The chronic bronchitis phenotype in subjects with and without COPD: the PLATINO study. Eur Respir J 2012; 40: 28-36.

9. Burgel PR, Nesme-Meyer P, Chanez P, Caillaud D, Carre P, Perez T, et al. Cough and sputum production are associated with frequent exacerbations and hospitalizations in COPD subjects. Chest 2009; 135 : 975-82.

10. Pelkonen M, Notkola IL, Nissinen A, Tukiainen H, Koskela H. Thirtyyear cumulative incidence of chronic bronchitis and COPD in relation to 30-year pulmonary function and 40-year mortality: a follow-up in middle-aged rural men. Chest 2006; 130: 1129-37.

11. Prescott E, Lange P, Vestbo J. Chronic mucus hypersecretion in COPD and death from pulmonary infection. Eur Respir J 1995; 8: 1333-8.

12. Speizer FE, Fay ME, Dockery DW, Ferris BG., Jr. Chronic obstructive pulmonary disease mortality in six US cities. Am Rev Respir Dis1989; 140(3 Pt 2): S49-S55.

13. van der Schans $\mathrm{CP}$. Conventional chest physical therapy for obstructive lung disease. Respir Care 2007; 52: 1198-206.

14. Valderramas SR, Atallah AN. Effectiveness and safety of hypertonic saline inhalation combined with exercise training in patients with chronic obstructive pulmonary disease: a randomized trial. Respir Care 2009; 54: 327-33.

15. Melloni B, Germouty J. The influence of a new beta agonist: formoterol on mucociliary function. Rev Mal Respir 1992; 9: 503-7.

16. Hasani A, Toms N, Agnew JE, Sarno M, Harrison AJ, Dilworth P. The effect of inhaled tiotropium bromide on lung mucociliary clearance in patients with COPD. Chest 2004; 125: 1726-34.

17. Calverley P, Pauwels R, Vestbo J, Jones P, Pride N, Gulsvik A, et al. Combined salmeterol and fluticasone in the treatment of chronic obstructive pulmonary disease: a randomised controlled trial. Lancet 2003; 361: 449-56.

18. Chong J, Poole P, Leung B, Black PN. Phosphodiesterase 4 inhibitors for chronic obstructive pulmonary disease. Cochrane Database Syst Rev 2011; CD002309.

19. Fabbri LM, Calverley PM, Izquierdo-Alonso JL, Bundschuh DS, Brose M, Martinez FJ, et al. Roflumilast in moderate-to-severe chronic obstructive pulmonary disease treated with longacting bronchodilators: two randomised clinical trials. Lancet 2009; 374: 695-703.

20. MacNee W. Oxidants/antioxidants and COPD. Chest 2000; 117(5 Suppl 1): S303-17.

21. Decramer M, Rutten-van Mölken M, Dekhuijzen PN, Troosters T, van Herwaarden C, Pellegrino R, et al. Effects of N-acetylcysteine on outcomes in chronic obstructive pulmonary disease (Bronchitis Randomized on NAC Cost-Utility Study, BRONCUS): a randomised placebo-controlled trial. Lancet 2005; 365: 1552-60.

22. Zheng JP, Wen FQ, Bai CX, Wan HY, Kang J, Chen P, et al. Twice daily N-acetylcysteine $600 \mathrm{mg}$ for exacerbations of chronic obstructive pulmonary disease (PANTHEON): a randomised, double-blind placebo controlled trial. Lancet Respir Med 2014; 2: 187-94.

23. Seemungal TA, Wilkinson TM, Hurst JR, Perera WR, Sapsford RJ, Wedzicha JA. Long-term erythromycin therapy is associated with decreased chronic obstructive pulmonary disease exacerbations. Am J Respir Crit Care Med, 2008; 178: 1139-1147.

24. Albert RK, Connett J, Bailey WC, Casaburi R, Cooper JAD, Criner GJ, et al. COPD Clinical Research Network. Azithromycin for prevention of exacerbations of COPD. N Engl J Med 2011; 365: 689-98.

25. Chen P, Deng Z, Wang T, Chen L, Li J, Feng Y, et al. The potential interaction of MARCKS related peptide and diltiazem on acroleininduced airway mucus hypersecretion in rats. Int Immunopharmacol 2013; 17: 625-32.

26. BioMarck Pharmaceuticals. BioMarck Pharmaceutical Reports Phase II Study Results for COPD Inhalation Solution [EB/OL]. Raleigh, NC: BioMarck Pharmaceuticals; 2011. Available at: http://www.biomarck. com/downloads/biomarck-pharmaceuticals-reports-phaseii.swf. Access on October 26, 2013

How to cite this article: Tian $\mathrm{P}$, et al. Clinical significance of airway mucus hypersecretion in chronic obstructive pulmonary disease. $\mathrm{J}$ TransI Intern Med 2015;3:89-92 